\title{
1. Setting base pay rates: integrating compensation practice with human capital value creation and value capture
}

Samantha A. Conroy

Compensating employees is one of the costliest activities for an organization. In fact, the average employee compensation cost is approximately 36 dollars per hour worked; wages and salaries alone account for 68 percent of the money spent on employee compensation (Bureau of Labor Statistics, 2017). Beyond cost, compensation matters to employees. Voluntary turnover has a relationship of $r=-0.15$ with pay satisfaction according to meta-analysis findings (Williams et al., 2006), and the economic status of most individuals is tied to their compensation.

The human capital literature has acknowledged the importance of compensation (e.g., Harris and Helfat, 1997), and compensation has figured prominently in frameworks on human resource configurations (Lepak and Snell, 2002). For example, internally equitable pay, externally equitable pay, and various pay bases have been central factors in empirical work on human resource configurations (Toh et al., 2008). Coff (1997) noted that focusing on employee pay perceptions, such as pay satisfaction and internal comparisons, is a potential human capital retention strategy. Yet, the nuances of compensation relevant to compensation researchers have rarely been sufficiently integrated with the nuances of the strategic human capital literature.

Compensation design involves many strategic choices, such as decisions about job evaluation, merit pay, and market matching (Balkin and Gomez-Mejia, 1987; Gerhart and Rynes, 2003). One strategy of practical importance often neglected by compensation researchers is base compensation determination, i.e., the approaches used to designate "the cash compensation that an employer pays for the work performed" (non-contingent pay; Milkovich et al., 2014: 14). This neglect is in spite of base pay being one of the largest components of compensation for many jobs, especially those jobs of most employees (i.e., non-executives; Bureau of Labor Statistics, 2017). Perhaps this lack of attention is due to a myth that base pay is determined completely by market forces, and thus cannot be a source of competitive advantage (i.e., above average performance, as defined by Barney and Wright, 1998).

Research over the last two decades on strategic human capital militates against the myth that base pay is not relevant to competitive advantage. For example, Coff examined firm coping strategies for human capital management dilemmas. Within this investigation, Coff explained, "pay differentials within the firm may be more important than the pay relative to the labor market. This, in turn, implies that firms can increase pay satisfaction without competing with other employers" (1997: 383). Decisions around base pay are not simply market and cost concerns, and these decisions may relate to competitive advantage through human capital value creation and capture (i.e., respectively, increased use value and decreased costs associated with human capital, as defined by Chadwick, 2017). 
Interestingly, when employees are hired for jobs, their use value or potential value creation in the firm is unknown. That is, information asymmetry dominates the hiring process (Chadwick, 2017; Chadwick and Dabu, 2009). Organizations have reasonably clear information on the job that will be filled by the applicant and the context of that job, on the one hand, and somewhat vague information on the potential applicant's knowledge, skills, abilities, and other characteristics (KSAOs), on the other hand. Potential hires have reasonably clear information on their own KSAOs and somewhat vague information on the context of the job they will fill. This means that at the moment a base pay determination is made, both parties lack important information.

The goal of this chapter is to illuminate the process of base pay determination at the entry stages of employment. I integrate strategic human capital and base compensation knowledge to answer the questions: How do different approaches to base pay determination contribute to competitive advantage through value creation and capture? How can these processes account for the potential of a hire to contribute to unit-level human capital resources? In order to manage the scope of this endeavor, I focus on the processes that influence individual base pay for external hires upon entering the organization (e.g., jobbased pay rates, individual pay adjustments and negotiations), rather than the ongoing process of negotiating and adjusting base pay over time for current employees (e.g., merit pay cycles and other performance-based pay or promotion practices). However, given my goal of addressing competitive advantage, I do note the implications of selected base pay approaches to longer-term value creation and capture.

I begin with a brief overview of the relevant strategic human capital literature. Then, I review the base compensation literature and the primary base pay approaches used by organizations today. The rest of the chapter is devoted to the value creation potential, value capture potential, and problem areas of three main factors that influence base pay setting (i.e., job evaluation, market pricing, and individual job offers). Finally, I discuss the implications and limitations of this integration.

\section{COMPETITIVE ADVANTAGE THROUGH STRATEGIC HUMAN CAPITAL RESOURCES}

Human capital has been defined as the knowledge, skills, abilities, and other characteristics of individuals, which can contribute to firm competitive advantage due to difficulty in imitation by other firms (Campbell et al., 2012). In a comprehensive discussion around how to define human capital, Ployhart et al. expanded this definition to consider multiple levels, focusing on the concept of human capital resources (HCRs) - "individual or unitlevel capacities based on individual KSAOs that are accessible for unit-relevant purposes" (2014: 374). In essence, human capital can contribute to competitive advantage, and these contributions are not simply through individual contributions but also through capacities at higher levels.

Ployhart et al. further distinguished between HCRs that contribute to competitive parity and strategic HCRs that contribute to competitive advantage. Competitive parity involves performance meeting that of competitors and the absence of a competitive disadvantage, and exists when a firm has a valuable resource; competitive advantage refers to performance above average, and requires both valuable and rare resources; sustained 
competitive advantage refers to above average performance over longer periods of time, and requires valuable, rare, and difficult to imitate resources (Barney, 1991; Barney and Wright, 1998).

Another important distinction in the literature exists regarding general and firmspecific skills (Barney and Wright, 1998). This distinction refers to the difference between skills that can be applied across firms (e.g., general skills like accounting knowledge) and those that are specific to the firm (e.g., firm-specific skills like understanding organizational procedures and navigating organizational culture). Much of the literature assumes that firm-specific skills are much more likely to contribute to sustained competitive advantage than general skills; however, Campbell et al. made a compelling case that these models are limited. Specifically, the conditions necessary for this logic to hold include: 1) exchange value equal to or less than use value of human capital;2) tightly coupled exchange value and firm-specificity of skills; and 3) worker costs to moving greater than the desire to move. Ployhart et al. also questioned the assumption that general skills do not contribute to competitive advantage because combinations of general skills can create difficult to replicate unit-level capacities. Essentially, the firmspecificity of skills may not be the key to explaining how human capital can be a source of sustainable competitive advantage; and in fact, under certain conditions, general skills may be a source of sustained competitive advantage. Altogether, this indicates that an assumption that general skills can be easily priced and move smoothly across organizations is untenable.

Both Coff (1999) and Chadwick explored how firms derive human capital rents - i.e., economic profits drawn from human capital. Two avenues of human capital rent have been central to such theorizing - those associated with value creation and those associated with value capture. Value creation refers to increasing the use value of human capital, and can be increased through worker complementarities (Chadwick, 2017; see also Ployhart et al., 2014). Value capture refers to reducing the costs associated with human capital. A primary avenue to value capture is to prevent employees from taking created value for themselves, i.e., preventing turnover (Chadwick, 2017). Another avenue to value capture is reduction of administrative costs associated with human capital (Chadwick, 2017).

Value creation and capture for firms are complicated by the fact that employees have free will and ownership of their human capital, such that firms cannot be certain that employees will both generate value and maintain membership within the organization (Chadwick, 2017; Coff, 1997, 1999). Chadwick noted that it is because of these issues that firms must consider both the economic and affective aspects of employment. Similarly, Coff (1997) noted that while pay matters in employee decisions to move, loss or gain of psychic income matters as well (i.e., the instrumental value of pay is not the only consideration in employee moves).

This brief review summarizes a few key underpinnings to HCRs that will be important to developing an understanding of base pay determination. One, HCRs, which exist at multiple levels, can be used to attain competitive parity or competitive advantage (Ployhart et al., 2014). Two, general skills and firm-specific skills can both contribute to competitive advantage (Campbell et al., 2012; Ployhart et al., 2014). And, finally, the contribution of HCRs to firm rents occurs through value creation and value capture. 


\section{HOW DO DIFFERENT APPROACHES TO BASE PAY DETERMINATION CONTRIBUTE TO COMPETITIVE ADVANTAGE THROUGH VALUE CREATION AND CAPTURE?}

To have a discussion about base pay determination (i.e., the process of setting base pay rates), we must first establish what is meant by base pay and what the base pay setting process typically looks like. Base pay refers to compensation in exchange for work, i.e., salary and wages. It is not inclusive of incentives or other forms of behavior-dependent pay; nor is it inclusive of benefits. Base pay simply refers to the hourly or annual compensation paid to employees for doing their job (Milkovich et al., 2014).

Base pay is often conceptualized at the organization level as the firm's pay structure i.e., "the array of pay rates for different work or skills within a single organization" (Milkovich et al., 2014: 72) - or, per Gerhart and Rynes (2003: 81), the "relative pay within organizations." Most research on base compensation has focused on the size of pay differences and the basis of these pay differences within pay structures - i.e., the pay dispersion literature (Conroy et al., 2014; Trevor et al., 2012).

In practice, a typical approach to base pay involves a graded or banded structure where jobs are placed in grades or bands with other equivalently valued jobs. These grades have rates associated with them based on the value assessed for the job, which is based on a job evaluation and/or market price. This value is represented as a minimum, midpoint, and maximum pay amount. That is, each grade or band has a pay range, and individuals placed in jobs are expected to be compensated within these pay ranges.

Individual job offers and negotiated base pay rates for external hires typically incorporate the following steps. First, the job an individual is going to fill has a grade and corresponding range associated with it, so the individual will, in most cases, be offered a base rate within that range. Second, where the individual falls within that range depends on the offer and negotiation process. Organizational representatives (e.g., compensation analysts, human resource generalists, hiring managers) decide on a job offer amount within the grade's pay range adjusted for factors such as the individual's KSAOs and the current market pressure for the specific job. Finally, in some cases, a negotiation process ensues between the applicant and the organization to determine the final base pay for the new hire. Whether or not a firm will negotiate is both firm- and job-specific (Michelacci and Suarez, 2006).

Researchers have separated base pay issues into vertical concerns (i.e., between-job valuation differences) and horizontal concerns (i.e., within-job valuation differences) (Gupta et al., 2012). These foci are often separate areas of study - e.g., horizontal (Shaw and Gupta, 2007) or vertical (DeVaro, 2006). In this chapter, I address both because the processes associated with each ultimately determine the pay rate of an external hire. I separate these processes into different sections (i.e., vertical and horizontal) for conceptual clarity. In what follows, the processes of each are discussed, and then related to value creation and value capture.

\section{Vertical Pay Variations: Job-Based Pay Setting}

Most organizations use a job-based system for determining base pay (Lazear, 1992). The bulk of the determinant of a person's pay is the value assigned to their job, defined as the 
set of work in which they are engaged. For example, a company may assign a value of $\$ 65,000$ to the job of manager with a range of pay of $\$ 55,000$ to $\$ 75,000$. Any employee hired to be a manager would be paid somewhere in this range. So, the largest proportion of an employee's base rate is based on the job that he or she fills. In fact, Lazear (1992) reported that 95 percent of variance in monthly pay was due to the job rather than withinjob differences in a sample of over 19,000 employees. Alternatively, some organizations have skill-based pay systems - e.g., pay is based on the number of skills an employee has (Lawler et al., 1993; Mitra et al., 2011), but this approach is much less common. Furthermore, vertical differences are typically viewed as across-job differences based on job evaluations and market forces (Gupta et al., 2012). As such, I focus on setting base pay in job-based pay systems here.

Job-based pay approaches require an assessment of the content and value of work (Milkovich et al., 2014). Any assessment requires that the organization complete a process to clarify what the work entails for each job in the organization (i.e., job analysis) as a starting point. Following this job analysis, two considerations have traditionally gone into this assessment process - job evaluations and market prices. Job evaluation processes focus on internal alignment (i.e., job value in comparison to other jobs within the company), while market pricing processes focus on external alignment (i.e., job value in comparison to the same job in other companies).

There are various methods of job evaluation, including classification, point factor, and ranking. Job evaluation procedures focus on organizational strategy and culture to understand how work should be valued. In the process of job evaluation, "raters typically assign a score that is intended to reflect the relative value of each job to the firm. Because of unique factors such as business strategy or organizational structure, this relative value may differ across employers" (Gerhart and Rynes, 2003: 85). Still, it would be almost impossible for organizations to solely focus on internal value since they must compete with other firms in the labor market to obtain talent. Thus, job evaluation is combined with market pricing to determine a job's base dollar value in an organization. Market pricing involves assessing the value of a job on the market and assigning that value as the "market price" for the work. ${ }^{1}$ The process of determining the market price involves an information search to find relevant competitors, equivalent jobs, and the associated pay rates. By engaging in this process, organizations are able to address the importance of the labor market in the flow of talent.

Limited research has been conducted on job evaluation and market pricing (for a recent exception, comparing job-based methods to skill-based pay, see Mitra et al., 2011). In the early 1990s, a conceptual/theoretical debate around base pay setting ensued with a focus on the value of job evaluation, a form of job-based pay, as compared to skill-based pay, a form of person-based pay (Barrett, 1991; Gupta and Jenkins, 1991; Mahoney, 1991). Despite this "raging controversy" (Gupta and Jenkins, 1991: 92), which often leaned toward skill-based pay as a more capable approach to compensation, job-based pay remains the primary and most common approach to compensation.

In a rare empirical study on the topic of job evaluation and market pricing, Weber and Rynes (1991) assessed managerial decision making regarding job valuation. Their primary finding was that market rates were more important than job evaluation information for decision makers. It appears that since the publication of the Weber and Rynes's paper, the trend has accelerated (SHRM, 2012). In particular, many organizations have 
moved to a market pricing only system, basing their entire job-based pay structure on "external market forces" (Milkovich et al., 2014: 289). A recent WorldatWork survey (2016) indicated that 91 percent of organizations used market pricing in some form to determine the relative value of jobs, while only 44 percent used classification, point factor, or ranking - indicating that a large portion of base pay structures are entirely market-based. Still yet, Gerhart and Rynes note that "organizations seem to have at least some flexibility to set unique internal pay rates, and in fact they often exercise this flexibility" (2003: 87).

The spectrum of job-based pay design emphasis ranges from a system entirely focused on internal worth to a system entirely focused on external worth. Traditionally, systems have fallen somewhere in the middle of this spectrum, combining internal and external factors with varying levels of emphasis. Most base pay systems today are either: 1) a combination of job evaluation and market pricing, in which both internal and external considerations are incorporated; or 2) market pricing only, in which only external considerations are incorporated (Milkovich et al., 2014; WorldatWork, 2016). Almost no systems, to my knowledge, are job evaluation focused alone without market consideration.

Given the lack of research on job-based pay design, the significant costs associated with base pay, and the trend toward entirely market-based systems of job pay determination, it is important to take a moment to consider the strategic implications of job-based pay design. Are market-based systems actually ideal for value capture and creation? While very few scholars have addressed this issue, the one place I could find where concerns about the trend toward full market pricing are raised is the textbook Compensation (Milkovich et al., 2014) used in many total rewards college classes in the United States. In particular, the authors scratch the surface of the issue by briefly noting that full market pricing prevents the pay structure from being a source of competitive advantage since market pricing removes firm pay structure and organizational strategy alignment. I explore potential explanations for these claims in the following section. I also explore other processes and pitfalls related to job evaluation and market pricing. But first, a few assumptions are noted.

First, my analysis assumes base pay within markets where firms may choose the amounts and levels of pay for those they employ - i.e., not countries where amounts and levels are dictated (Milkovich et al., 2014: 77). Building on the first assumption, my analysis assumes that external factors - such as government policies, laws, and regulations - are held constant. Finally, my analysis is focused on "regular people" pay structures, not executive pay structures or base pay for temporary or contract work.

An internal focus alone (i.e., job evaluation only) is a theoretical, but not practical, concept in that most organizations use some market data in their job pricing models. However, to ensure conceptual clarity, I address the issues of value creation, value capture, and other pitfalls for job evaluation and market pricing separately.

\section{Job Evaluation Approaches}

\section{Value creation}

Job evaluation is an inherently inward-focused process (Milkovich et al., 2014). Organizational leaders must engage in a process that clarifies exactly what factors are of value to the firm and how important those factors are. The link between the firm's values 
and the job evaluation process is exemplified in a points method job evaluation system in which organizations identify compensable factors - i.e., "characteristics in the work that the organization values, that help it pursue its strategy" (Milkovich et al., 2014: 145) - and assign these factors weight based on their importance to the firm.

As an example of the value assignment process, a company like Southwest Airlines may develop a job evaluation system with an emphasis on customer relationship building as a key compensable factor that is highly weighted, while another airline may value this factor much less. This emphasis on organizationally valuable factors provides an opportunity for strategic alignment of the compensation system, and potential value creation, by emphasizing and valuing those components of work that are most important to the firm gaining a competitive advantage. When the organization's base pay is aligned with its values and strategy, it can attract the highest-quality applicants for its most strategically relevant functions. Thus, job evaluation is unique to the organization, and can assign value to work based on the extent of strategically required human capital for jobs.

In addition, designing a job evaluation system specific to the organization allows a firm to create and "leverage idiosyncratic advantages with respect to labor market frictions, such as offering an attractive organizational culture that serves as meaningful and unique" (Chadwick, 2017: 504). Because the job evaluation system is unique to the organization, it can contribute to the building of a strong and unique organizational culture. As the values of the organization determine what work will be paid and how limited resources are distributed, this can be a sense-giving process (Ashforth et al., 2008), which serves to inform employees of the organization's culture.

A third avenue to value creation through job evaluation is related to its relationship with internal alignment. Specifically, job evaluation focuses on how to assign value to work based on comparisons to other jobs internally. This focus has the potential to increase employee perceptions of internal equity (i.e., the fairness of the pay system when making internal comparisons), which is important to employees. For example, in a study of salespeople, internal salary equity was a significant predictor of job satisfaction (Livingstone et al., 1995).

Finally, as described by Ployhart et al. (2014), strategic HCRs involve both individual and unit-level capacities. Unit-level capacities require efficient functioning within groups in the organization. When the job evaluation process promotes feelings of fairness and satisfaction with base compensation within organizational groups, individuals within groups are more likely to collaborate and develop relationships within those groups (Conroy and Gupta, 2016; Sinclair, 2003). Ultimately, these improved group dynamics may improve HCRs.

Internally developed job evaluation approaches have the potential to contribute to value creation through strategic alignment, organizational culture, internal equity, and, ultimately, human capital resources. Because the approach is unique to the firm, it is hard to imitate in other organizational contexts.

\section{Value capture}

Value capture can occur through reducing turnover and administrative costs (Chadwick, 2017). While the administrative costs of job evaluation will be noted under pitfalls, turnover reduction may be related to job evaluation in two main ways. First, by clarifying value 
in the work of the firm, organizations can be expected to pay more for the jobs containing the highest levels of strategic human capital. Assuming limited resources, it is not that job evaluation would involve paying all jobs more; it is that job evaluation involves paying jobs requiring higher levels of strategic human capital more than jobs requiring lower levels. Research has shown pretty clearly that higher pay levels are associated with lower turnover (Gerhart and Rynes, 2003; Rubenstein et al., 2018). So, a firm may not reduce turnover in total, but strategically aligned job evaluation may lead to lower turnover in the most important firm roles.

Second, because job evaluation can create internal equity perceptions within the organization and can contribute to the development of organizational culture, the use of job evaluation as part of an overall human resource system may contribute to affective ties to the organization. Chadwick (2017) claimed that such affective ties may be key to leveraging labor market frictions because they cannot be easily imitated by a competitor. Job evaluation systems treat jobs in the organization as unique and specific to the organization, rather than as exchangeable with the market. This means it is possible that organizations are signaling the importance of the most strategically relevant human capital through the job evaluation system in a different way than in a market pricing system.

Related to this, Coff viewed "firm-specific compensation" as a means toward creating a psychic cost to exiting the organization, thus reducing turnover (1997: 384). Employees may develop a preference for how an organization values and designs work, and this preference could influence the required price for the employees to move to another organization. By nurturing a set of organizationally central values (Coff, 1997) in the job evaluation process, the base pay system can differentiate the organization from others.

Internally developed job evaluation approaches have the potential to contribute to value capture through strategic alignment and affective ties. Because the approach is unique to the firm, it is hard to imitate in other organizational contexts.

\section{Pitfalls}

Taking an entirely job evaluation-based approach to base pay has a number of downsides, and in fact may be so foolish that almost no companies use this approach alone (Romanoff, Boehm, and Benson, 1986). The primary problem is that job evaluation alone ignores the labor market associated with work. Thus, it is possible that a job evaluation system could become so unhinged from the labor market that an organization could not attract employees to join the firm, or only attract employees within a few very specific jobs. This of course would be an example of under-compensating most employees. Another possibility would be over-compensating employees to such an extent that the firm is not capturing any value at all.

A second problem that arises with a solely job evaluation-based structure is that administrative costs are likely to be high, and administrative costs reduce value capture (Chadwick, 2017). Job evaluation requires a time-intensive process of identifying compensable factors, weighting factors, and then assessing each job according to the developed scale. Often organizations, recognizing the importance of internal equity and fairness of the system, will engage multiple stakeholders in the evaluation process. Given these stakeholders tend to be high in the organizational hierarchy, their time and 
involvement in the process is an expensive investment by the firm in comparison to market pricing, which can be completed by one or two analysts. Another related concern is the potential for political manipulation in the job evaluation process, such that it may not have the intended alignment with organizational strategy in organizations, and rather may be defined by high levels of politics (Gupta and Jenkins, 1996; Welbourne and Trevor, 2000).

Another variable that could interfere with the value creation and value capture proposition of a job evaluation system would be the implementation of an easily replicable system. In particular, some consulting companies have "off-the-shelf" evaluation systems which firms can buy and implement. In this case, the system no longer connects to the organization strategy in a unique way. Perhaps most importantly, the system becomes highly replicable and, thus, unable to contribute to a sustainable competitive advantage.

Organizations must be wary of extreme over- or under-compensating, administrative management costs, and using easily replicable systems when using job evaluation to set base pay.

\section{Market Pricing Approaches}

\section{Value creation}

Market pricing is an outward-focused process to assess the value of work. Unlike job evaluation, the primary concern is obtaining information about the value of jobs on the labor market (Barcellos, 2005). Once values are obtained, firms can choose to match, lag, or lead these values (Klaas and McClendon, 1996).

Of course, the greatest strength of a market pricing approach is that firms are more aligned with the labor market. It is a potential means of avoiding over- or undercompensating employees. Any benefit to value creation comes from the perceptions of potential and current employees that the firm is paying fairly as compared to the job market. As external comparisons do relate to pay satisfaction, employees may feel they are treated well by the firm when market pricing accurately values jobs on the labor market (Sweeney and McFarlin, 2005).

It is notable, however, that market pricing is likely to be imitable for a couple of reasons. One, most market data is obtained through surveys provided by third parties. Thus, the data obtained by one firm is likely the same as the data obtained by another firm, and these data may not be modified to match the actual human capital configurations of the focal organization. Two, the goal with market pricing is to assess the "true market price" of each job. While the market price is more a theoretical than an actual concept (Barcellos, 2005), it is noteworthy that all firms are seeking the same value. That is, any firm using a market pricing approach is seeking externally driven information using a common method. This approach can easily be replicated by other firms. At best, a competency in market pricing a job structure would lead to competitive parity; at worst, problems with inaccurate market pricing would lead to a competitive disadvantage. Market pricing is necessary, but unlikely to lead to competitive advantage.

Market pricing approaches have the potential to contribute to value creation due to the pay structure's relationship with external equity. However, this approach is not unique to the firm and is easily replicated in other organizational contexts. 


\section{Value capture}

Market pricing is likely attractive to many firms because it drives down the administrative costs associated with base pay systems. These administrative efficiencies occur for a few reasons. One, market pricing requires little input from stakeholders. Firm analysts can seek out market information and put a price on each job. This means there is a low time burden for most organizational members associated with the market pricing task.

Two, market pricing processes require relatively little maintenance beyond updating data. While this takes time for the compensation analyst, it does not require full system revisions or the associated processes to get organizational members to accept and agree upon the system. External pricing data is likely to be quickly accepted by organizational members to explain pay decisions, and conversations around the organization's values are not necessary. Thus, the only administrative cost of market pricing appears to be the purchase and management of market survey data, which, in comparison to the costs of job evaluation processes, seems a minor concern.

Again, as with the discussion of value creation using market pricing, the easy replication of this system is problematic. Any organization can access the administrative efficiencies of such a system, making this value capture easily imitable.

Market pricing approaches have the potential to contribute to value capture due to the pay structure's lower administrative costs. However, this approach is not unique to the firm and is easily replicated in other organizational contexts.

\section{Pitfalls}

A number of potential problems arise for firms when one considers a fully market-focused approach to base pay. First, market pricing is fully disconnected from anything that makes the firm unique. It is assumed that all work within the firm is the same as work performed outside of the firm. That is, work becomes a commodity despite the reality that organizations are unlikely to configure work in the same way (i.e., jobs are unlikely to be exact human capital matches across organizations). In fact, given that organizations can utilize HCRs for higher performance, external market data cannot accurately assess a job's value to its unit and to the firm. The firm's culture, values, and strategy are, at most, incorporated by the lag, lead, or match pay decision, but are not incorporated in the organization's actual valuation of work. And, as noted earlier, all of these are easily replicated organizational processes.

Second, market pricing is unlikely to create affective ties to an organization. As the work of a job is "priced" on the market rather than with respect to the organization or the individual's human capital, there is the potential for people to feel more like widgets than individuals of relevance and importance to the organization. Thus, little affective connection would be created through a market pricing approach.

Finally, while rarely discussed, market pricing processes are not without problems. The existence of a true market price is mostly theoretical. Each analyst pricing jobs will engage in this process with their own biases and limitations. Bounded rationality prevents perfection in the process (Conlisk, 1996). And, there are information problems throughout the process. In the process of gathering market pay data, firms providing data may limit or alter the information provided, and outliers (i.e., unique incumbents in jobs) may pull prices away from the true market price. Furthermore, the valuation process can never 
entirely explain human capital value in use as each organization's use of human capital will be different. That is, use value can vary across firms for the same skills based on how skills are used (Campbell et al., 2012: 379; Ployhart et al., 2014). So, while a strength of market pricing is the potential for alignment with external prices, even this cannot be assured due to information problems and bounded rationality.

Organizations must be wary of disconnecting from organizational strategy and culture, weak affective ties, and matching inaccuracies when using a market pricing approach to set base pay.

\section{Horizontal Pay Variations: Person-Based and Within-Grade Pay Setting}

The preceding section addressed the process through which organizations determine the pay rate and range for a particular job. Differences in compensation across jobs can be understood based on this analysis; however, differences in compensation rates across people within jobs cannot. This section is intended to address those differences across people upon firm entry. That is, the pay associated with a new external hire combines the job's value with the person's specific value within the job.

I note that the concept of horizontal, i.e., within-job, pay variations in the literature is typically associated with current employees, such that the primary bases for these variations are performance and seniority, among others (Gupta et al., 2012). The bases considered when we look at pay rates assigned upon hire include anticipated value creation (i.e., expected performance, productivity within the organizational context). Here, I address the processes related to person-specific new external hire pay rates, so anticipated value creation is the primary concern.

Workers even within a job can be heterogeneous in their contribution to the organization (Lazear, 1992). This heterogeneity depends on a multitude of factors - job content, monitoring, recruiting strategies - and has been noted in prior management work as SDy (i.e., the standard deviation of performance at work; Hunter and Schmidt, 1983). An organization can choose whether to make adjustments to the job-based pay rate as a result of such differences; if adjusting occurs, then the firm can choose whether or not there will be bargaining (i.e., negotiating) in the base pay setting process. The approach an organization takes in deciding the hiring rate for workers is likely to depend on this heterogeneity, with greater heterogeneity associated with a firm's decision to bargain with hires to determine new hire compensation (Michelacci and Suarez, 2006). For example, a retail firm is unlikely to negotiate the rate of pay for a cashier, but may negotiate the rate of pay for a marketing manager. Both the economics and management literatures suggest that organizations will vary in the extent to which they negotiate pay rates at the individual level and that, within organizations, the likelihood of negotiating pay rates will depend on the specific job (Michelacci and Suarez, 2006).

In addition to research on whether or not a firm will bargain, there is a literature on candidate and firm negotiation processes (e.g., Gerhart and Rynes, 1991; Marks and Harold, 2011; O'Shea and Bush, 2002). This work indicates that in a negotiation, there is uncertainty on both sides regarding the other party's "reservation point (the point at which the negotiator is indifferent between reaching a settlement and walking away from the negotiation) and target point (the negotiator's ideal or most preferred outcome)" 
(Galinsky and Mussweiler, 2001: 656). As a result the negotiation process is defined by uncertainty, as neither the company nor the potential hire has perfect information.

Controlling for the job-based rate in determining base pay rates for individuals entering a firm, organization leaders and representatives make a few decisions. One, will the job-based pay rate be adjusted to account for the specific potential value creation of a given hire? Two, will bargaining occur at all? Three, what are the reservation and target points if negotiation is to occur? That is, at what point is the firm willing to move on to a next potential hire rather than continue the bargaining process with a candidate, and at what point is the firm paying the ideal rate? To determine acceptable and ideal wage rates, a firm must assess the value of the hire without having certainty of what their use value will be.

One problem associated with this external hiring and pay setting process has been termed the "market for lemons" problem, which essentially proposes that since candidates have more information about their own value than employers, employers will undercompensate new hires to avoid overpaying for a "lemon" (Akerlof, 1970). In turn, the best potential hires will not be available on the market because there is a penalty to job change (Akerlof, 1970; Coff and Kryscynski, 2011). This highlights a few assumptions: 1) candidates have more information about their contribution to value creation; 2) firms will tend toward lower acceptable/ideal rates; and 3) there is a higher proportion of undesirable than desirable candidates as high performers opt out of the search.

Counter to the ideas around the "market for lemons," there is research to show that firms tend to pay more for external hires than internal hires even in the same job, but, in the end, they "pay more to get less" (Bidwell, 2011: 369). This suggests that organizations may not be doing a good job assessing potential value creation in the external pay setting process and/or that they are missing out on value capture with external hires in comparison to internal hires. I will argue below that despite the apparent problems in the pay setting process, given the information firms have about context, firms may be able to gain by accurately assessing candidates' potential value creation and adjusting rates based on this information.

In practice, job offer negotiations are completed by various organizational representatives (Malhotra, 2014), are idiosyncratic to the negotiators and the biases associated with these individuals (Anderson and Thompson, 2004; Olekalns and Smith, 2009), and are controlled by pay ranges (Milkovich et al., 2014). Thus, it seems unlikely then that negotiations are done consistently, meaning the negotiation process itself is heterogeneous. Thus, the value creation and capture for each external hire will be different when bargaining is used.

For the following section, I assume work is such that there is heterogeneity of employee contribution, and discuss how adjustments to base pay rates for individual employees can lead to value creation and capture. I will continue to maintain the organization-level focus as used in the job-based section by focusing on organizational practices around making adjustments and engaging in bargaining with applicants. However, examples at lower levels are inherent in the discussion of individual value assessment. It is also important to note that organizations may vary in the extent to which they adjust pay from the job-based rates depending on the job. 


\section{Value creation}

One tension between compensation in practice and how the literature tends to treat compensation of human capital is that, in practice, base pay is primarily determined around the job (discussed at length earlier in this chapter). However, there is some leeway in that assignment within pay ranges. Firms with policies that allow for adjustments and/or bargaining have the potential to better narrow in on the actual value creation of the hire.

Coff and Kryscynski noted that individuals have "unique mixes of human capital" (2011: 1433); this uniqueness is inconsistent with the common job-based approach to pay, which assumes that value can be assessed based solely on job content. So, some individual adjustments at hire seem necessary to address the inherent uniquenesses of human capital. But the potential value creation of these processes requires accurate human capital assessments by the firm, which "are difficult to observe and evaluate ex ante" (Coff and Kryscynski, 2011: 1433).

An important question at this point is: what is an accurate assessment of human capital value? Drawing on the concepts of Chadwick (2017), it would be fair to say that an accurate assessment exists when the firm is able to evaluate the actual value creation of an individual. For a new hire this would be an accurate assessment of future value creation of the individual in the job. It seems clear that each person in a job in an organization, given each individual's unique set of skills, will vary. This is especially the case for jobs that are not highly monitored. This variance is accommodated by pay structures as the pay range increases as the grade level of the job increases (Milkovich et al., 2014).

In reality, value creation by any individual cannot be perfectly assessed in most organizations. This is particularly true when you consider the role of time and social complexity in value creation. For example, Coff and Kryscynski suggested that ability and willingness to learn firm-specific skills would increase the value of a hire over time. Should organizations include this in their value assessments and pay extra for those who will invest in these skills? Coff and Kryscynski also noted that individuals who act as boundary spanners have value beyond their role and potential beyond the apparent value at hire. Should firms assess this value and incorporate it into value assessments? And, when we consider HCRs (Ployhart et al., 2014), the value of an individual becomes even murkier. Here organizations have the upper hand in assessing an employee's value to the extent they can assess how this person will fit within the group and organization to contribute to unit-level capacities and potential strategic HCRs (see Kehoe and Bentley, Chapter 16 this volume).

Given the clear difficulties of assessing the value creation of new hires, it appears that firms able to do it well may have a competitive advantage over firms that cannot. These assessments allow the firm to compensate new hires more consistently with their worth and/or derive clear strategies around pay for value creation, potentially attracting the highest contributors and avoiding those with low value creation capacity. It is particularly important that adjustments are made with context as a central consideration. That is, organizations must consider the individual's potential HCR contribution. This requires considering multiple levels of value creation potential, i.e., individual KSAOs that contribute to the unit and how these individual KSAOs complement or detract from the unit-level capacities.

Note that I am not suggesting that alignment of pay and value creation would be equal; the firm could still pay slightly less than value creation. Market inaccuracies occur for 
human capital, so attracting the best talent with these rates may be possible. Given the firm-specificity of such assessments - i.e., the assessments must incorporate the value of the skills within the firm given the complex social structures of the firm (see Chapter 16) - these assessments cannot be easily copied by other firms.

Individual adjustments to job-based pay rates can contribute to value creation when adjustments are aligned with use value of human capital. Particularly important to the success of individual adjustments is assessment of the individual's contribution to HCRs.

\section{Value capture}

As noted earlier, value capture can occur through preventing employees from taking their value with them and through reduction of administrative costs (Chadwick, 2017). The decision of a firm to adjust pay from the job-based rate or to engage in the bargaining process and attempt to accurately assess human capital value prior to employment will be administratively more costly than a decision to pay all hires the same amount. Thus, a decision to bargain does not benefit the firm in terms of administrative efficiencies. Rather, it is other considerations, the roles of individual adjustments and bargaining on potential turnover, that are most relevant.

Accurate assessments of value creation potential allow an organization to choose a strategy around pay and then consistently administer that strategy. Consistency and fairness are important to employees in regard to pay satisfaction and subsequent retention (Williams et al., 2006). That is, the closer a firm can get to accurately assessing value potential, the more consistent their negotiation process can be across hires. It may be that, rather than "bargaining" or "negotiating," "adjusting" base pay offers to be in alignment with expected value creation is the most effective approach since the power of the other party to affect the rate exists when bargaining occurs.

To the extent firms are able to make base pay decisions for external hires in line with the contribution that will occur upon hire, employees are more likely to feel fairly treated -i.e., social comparisons yield fair input/outcome ratios across employees in the job (Adams, 1965). Perceptions of fair treatment increase pay satisfaction (Williams et al., 2006) and ultimately reduce turnover (Rubenstein et al., 2018). Furthermore, if we consider the possibility that contribution to value creation ebbs and flows over time for any individual, individuals who feel they have been treated fairly in the past are more likely to remain, even in moments at which their value creation greatly exceeds that which they individually capture. Thus, a fair and well-aligned rate assigned at hire has the potential to yield greater value capture over time.

Individual adjustments to job-based pay rates can contribute to value capture by preventing excessive payments and reducing turnover.

\section{Pitfalls}

Though individual adjustments come with potential upsides of value creation and capture, there are downsides of which firms must be wary when selecting an adjustment strategy. One obvious pitfall is the cost of assessing each employee's potential value creation within the organizational context. Engagement in assessing value and then negotiating with employees can be costly. This may explain why we see broader ranges and more negotiating at higher levels (Milkovich et al., 2014). Firms choose to adjust 
only when human capital value creation is highly variable within a job (Michelacci and Suarez, 2006).

Beyond administrative costs, there are significant risks to engaging in bargaining. One is that the assessments of value may be incorrect. An organization's capability at assessing human capital value creation potential is critical to the success of this strategy. And, as noted in the value creation section, this assessment involves a great deal of forward-looking and context-dependent assessment (i.e., consideration of HCRs). These assessments are made with significant uncertainty regarding how the individual will integrate with the group. If these assessments are incorrect, the organization runs the risk of compensating good negotiators rather than valuable contributors to the unit's HCRs. Furthermore, inconsistencies in alignment of pay with value creation may create problems within the organization over time, where social comparisons of inputs (e.g., perceived value creation) and outcomes (e.g., base pay) lead to employee frustration with inequity (Adams, 1965).

A second risk is that bargaining or negotiating tends to be done by an organizational representative and is unlikely to be a consistent process. Rather, it is idiosyncratic to the particular negotiators involved. The intention of negotiators is likely to vary significantly (Kimmel et al., 1980). For instance, some negotiators engage in bargaining with the goal of a "win" (i.e., a distributive negotiation strategy), while others engage in bargaining with a more interpersonally focused definition of negotiation success (i.e., an integrative negotiation strategy; Kimmel et al., 1980). Those who enter the process to win may gain by offering a wage significantly lower than the actual value creation potential of the new hire. However, given what we know about the importance of affective connection to the organization impacting employee behaviors (Ashforth et al., 2008), the long-term effects of this strategy may be negative. This is because the employee is being under-compensated such that better alternatives may arise. As these alternatives become apparent to the employee, the fact that the individual may feel negatively toward the organization based on the negotiation experience makes them more likely to exit.

Organizations must be wary of administrative costs, inaccuracy of value creation assessments, and strained negotiations when individual adjustments to job-based pay rates are included in the base pay setting process.

\section{CONCLUSION}

The goal of this chapter was to explore base pay setting practices in organizations through the lens of human capital value creation and value capture. This work contributes to the bases of pay variation literature (e.g., Gupta et al., 2012) by addressing rarely considered bases. More often, this literature has focused on performance-based pay concerns. I hope to spur more attention on job evaluation, market pricing, and individual adjustment explanations for differences in pay. This exploration indicates that more work addressing strategic considerations in base pay setting processes is needed for a few reasons. One, clearly the base pay setting process is associated with some of an organization's largest expenditures. Two, the base pay setting process is not simply a process of finding a true market rate and offering that rate. Some jobs may be hard to price, and a true market price does not actually exist in many cases. Furthermore, when we consider use value 
and unit-level capacities specific to an organization, the importance of organizational assessments of value becomes apparent. Three, value creation and value capture issues are interwoven throughout the base pay setting process, from the job assessment to the individual offer.

While a number of potential factors associated with value creation and capture were identified here, much more work is needed. The factors identified here could benefit from empirical exploration. And, there may be value in investigating specific issues conceptually in more detail. For example, I noted the ebb and flow of value creation over time. How does the base rate set at hire relate to this ebb and flow as far as value appropriation for the organization? Do firms over- and underpay over time for the same employee depending on unit and organizational conditions? This is likely given that base rates are set based on the job more so than on the individual. Pay-for-performance (PFP) may be a way of creating alignment of value creation and pay over time (see Nyberg and Reilly, Chapter 23 this volume). For example, Lazear (2000) described implementation of piece rate plans leading to better firm outcomes and higher pay for the highest-performing employees. Yet, PFP is known to have significant challenges in implementation (Beer and Cannon, 2004), and, as explained earlier in this chapter, makes up a relatively small amount of compensation for most employees as compared to base compensation. Base pay is important to attracting talent (Chapter 23). Moving towards greater emphasis on variable pay is likely to reduce resources available for base pay, so research aimed at understanding how pay mix may relate to value creation and capture over time would address a complex issue.

Another question emerging is whether the administrative burdens associated with job evaluations and individual adjustments are worth the potential value creation benefits. It is possible organizations have moved toward market pricing, in practice, in order to avoid a competitive disadvantage and reduce costs. Perhaps job evaluation is higher risk, leading to competitive advantage or competitive disadvantage depending on multiple factors, including the quality of the process. We know the effectiveness of any pay plan depends on the organizational climate and culture (Mitra et al., 2011), so this factor must also be considered. We need a better understanding of both of these processes in organizations to address these conjectures. Yet, little work has explored base pay setting in the past two decades, especially job-based determinants of pay.

Given that HCRs are person- and unit-specific (Ployhart et al., 2014), I am left wondering why organizations continue to pay by the job. Might base pay need to take a new direction in practice? The skill-based pay versus job evaluation-based pay debate of the 1990s raised this same concern (e.g., Gupta and Jenkins, 1991). Following up on this debate, Mitra et al. demonstrated empirically the superiority of skill-based pay plans to job evaluation and market pricing plans, assuming fit with the organization's culture. Yet, little has changed as most organizations continue to take a market pricing approach to base pay. The changing nature of work from manufacturing to more knowledge-intensive jobs may make traditional skill-based pay difficult to implement in today's organizations. Though skill-based pay may not be the answer, organizations that can figure out how to compensate in alignment with human capital resources may be able to secure a sustainable competitive advantage. 


\section{CHAPTER SUMMARY}

\section{BOX 1.1 KEY TAKEAWAYS}

1. Organizational base pay setting processes are related to strategic human capital as these processes determine the alignment of human capital costs with human capital value creation and capture.

2. Using job evaluation to set base pay has greater potential for competitive advantage than market pricing, while market pricing is necessary to prevent competitive disadvantage. Setting base pay for the job has several limitations regardless of the approach, so adjusting for individual human capital is also a necessary consideration.

3. While organizations lack full information about an external hire's human capital, they have unique information about unit-level human capital resources and the potential of a specific hire to contribute to these resources. Thus, base pay setting processes should include assessment of a new hire's potential to contribute to HCRs.

\section{BOX 1.2 DIRECTIONS FOR FUTURE RESEARCH}

1. More research is needed exploring the base pay setting process. In particular, empirical work is needed in addressing how job evaluation, market pricing, and individual base pay adjustments relate to human capital value creation and capture.

2. The relationships between base pay and value creation should be studied over time to understand how ebbs and flows in value creation coupled with relatively unchanging base pay relate to human capital retention and value capture.

3. Models proposing how to compensate employees by moving beyond job-based paradigms and in light of insights on strategic human capital resources are needed.

\section{NOTE}

1. Here, the term "market pricing" refers to a well-known approach to base pay in organizations. This is not to be confused with the concept of market pricing as discussed in relational human capital models (Bridoux and Stoelhorst, 2016), though it would be reasonable to propose a market pricing approach to base pay fits with the market pricing relational model.

\section{REFERENCES}

Adams, J. S. (1965). Inequity in social exchange. In L. Berkowitz (ed.), Advances in Experimental Social Psychology (Vol. 2, pp. 267-99). New York: Academic Press.

Akerlof, G. (1970). The market for lemons. Quarterly Journal of Economics, 84(3), 488-500.

Anderson, C., and Thompson, L. L. (2004). Affect from the top down: How powerful individuals' positive affect shapes negotiations. Organizational Behavior and Human Decision Processes, 95, 125-39.

Ashforth, B. E., Harrison, S. H., and Corley, K. G. (2008). Identification in organizations: An examination of four fundamental questions. Journal of Management, 34(3), 325-74.

Balkin, D. B., and Gomez-Mejia, L. R. (1987). Toward a contingency theory of compensation strategy. Strategic Management Journal, 8(2), 169-82.

Barcellos, D. (2005). The reality and promise of market-based pay. Employment Relations Today, 32(1), 1-10. 


\section{Handbook of research on strategic human capital resources}

Barney, J. (1991). Firm resources and sustained competitive advantage. Journal of Management, 17(1), 99-120.

Barney, J. B., and Wright, P. M. (1998). On becoming a strategic partner: The role of human resources in gaining competitive advantage. Human Resource Management, 37(1), 31-46.

Barrett, G. V. (1991). Comparison of skill-based pay with traditional job evaluation techniques. Human Resource Management Review, 1(2), 97-105.

Beer, M., and Cannon, M. D. (2004). Promise and peril in implementing pay-for-performance. Human Resource Management, 43(1), 3-48.

Bidwell, M. (2011). Paying more to get less: The effects of external hiring versus internal mobility. Administrative Science Quarterly, 56(3), 369-407.

Bridoux, F., and Stoelhorst, J. W. (2016). Stakeholder relationships and social welfare: A behavioral theory of contributions to joint value creation. Academy of Management Review, 41(2), 229-51.

Bureau of Labor Statistics. (2017, December 17). Employer costs for employee compensation [Press release]. Retrieved from https://www.bls.gov/news.release/pdf/ecec.pdf.

Campbell, B. A., Coff, R., and Kryscynski, D. (2012). Rethinking sustained competitive advantage from human capital. Academy of Management Review, 37(3), 376-95.

Chadwick, C. (2017). Toward a more comprehensive model of firms' human capital rents. Academy of Management Review, 42(3), 499-519.

Chadwick, C., and Dabu, A. (2009). Human resources, human resource management, and the competitive advantage of firms: Toward a more comprehensive model of causal linkages. Organization Science, 20(1), $253-72$.

Coff, R. W. (1997). Human assets and management dilemmas: Coping with hazards on the road to resourcebased theory. Academy of Management Review, 22(2), 374-402.

Coff, R. W. (1999). When competitive advantage doesn't lead to performance: The resource-based view and stakeholder bargaining power. Organization Science, 10(2), 119-33.

Coff, R. W., and Kryscynski, D. (2011). Invited editorial: Drilling for micro-foundations of human capital-based competitive advantages. Journal of Management, 37(5), 1429-43.

Conlisk, J. (1996). Why bounded rationality? Journal of Economic Literature, 34(2), 669-700.

Conroy, S. A., and Gupta, N. (2016). Team pay-for-performance: The devil is in the details. Group and Organization Management, 41(1), 32-65.

Conroy, S., Gupta, N., Shaw, J., and Park, T. (2014). A multi-level approach to the effects of pay variation. Research in Personnel and Human Resources Management, 32, 1-64.

DeVaro, J. (2006). Strategic promotion tournaments and worker performance. Strategic Management Journal, $27(8), 721-40$.

Galinsky, A. D., and Mussweiler, T. (2001). First offers as anchors: the role of perspective-taking and negotiator focus. Journal of Personality and Social Psychology, 81(4), 657-69.

Gerhart, B., and Rynes, S. (1991). Determinants and consequences of salary negotiations by male and female MBA graduates. Journal of Applied Psychology, 76(2), 256-62.

Gerhart, B., and Rynes, S. (2003). Compensation: Theory, Evidence, and Strategic Implications. Thousand Oaks, CA: Sage.

Gupta, N., Conroy, S. A., and Delery, J. E. (2012). The many faces of pay variation. Human Resource Management Review, 22(2), 100-115.

Gupta, N., and Jenkins Jr, G. D. (1991). Job evaluation: An overview. Human Resource Management Review, l(2), 91-5.

Gupta, N., and Jenkins Jr, G. D. (1996). The politics of pay. Compensation and Benefits Review, 28(2), 23-30.

Harris, D., and Helfat, C. (1997). Specificity of CEO human capital and compensation. Strategic Management Journal, 18(11), 895-920.

Hunter, J. E., and Schmidt, F. L. (1983). Quantifying the effects of psychological interventions on employee job performance and work-force productivity. American Psychologist, 38(4), 473.

Kimmel, M. J., Pruitt, D. G., Magenau, J. M., Konar-Goldband, E., and Carnevale, P. J. (1980). Effects of trust, aspiration, and gender on negotiation tactics. Journal of Personality and Social Psychology, 38(1), 9-22.

Klaas, B. S., and McClendon, J. A. (1996). To lead, lag, or match: Estimating the financial impact of pay level policies. Personnel Psychology, 49(1), 121-41.

Lawler, E. E., Ledford, G. E., and Chang, L. (1993). Who uses skill-based pay, and why. Compensation and Benefits Review, 25(2), 22-6.

Lazear, E. P. (1992). The job as a concept. In W. J. Bruns (ed.), Performance Measurement, Evaluation, and Incentives (pp. 183-215). Boston, MA: Harvard Business School Press.

Lazear, E. P. (2000). Performance pay and productivity. American Economic Review, 90(5), $1346-61$.

Lepak, D. P., and Snell, S. A. (2002). Examining the human resource architecture: The relationships among human capital, employment, and human resource configurations. Journal of Management, 28(4), 517-43.

Livingstone, L. P., Roberts, J. A., and Chonko, L. B. (1995). Perceptions of internal and external equity as predictors of outside salespeoples' [sic] job satisfaction. Journal of Personal Selling and Sales Management, $15(2), 33-46$ 
Mahoney, T. A. (1991). Job evaluation: endangered species or anachronism? Human Resource Management Review, 1(2), 155-62.

Malhotra, D. (2014). 15 Rules for negotiating a job offer. Harvard Business Review, 92(4), 117-20.

Marks, M., and Harold, C. (2011). Who asks and who receives in salary negotiation. Journal of Organizational Behavior, 32(3), 371-94.

Michelacci, C., and Suarez, J. (2006). Incomplete wage posting. Journal of Political Economy, 114(6), 1098-123.

Milkovich, G. T., Newman, J. M., and Gerhart, B. (2014). Compensation (11th edn). New York: McGraw-Hill.

Mitra, A., Gupta, N., and Shaw, J. D. (2011). A comparative examination of traditional and skill-based pay plans. Journal of Managerial Psychology, 26(4), 278-96.

Olekalns, M., and Smith, P. (2009). Mutually dependent: Power, trust, affect and the use of deception in negotiation. Journal of Business Ethics, 85(3), 347-65.

O'Shea, P. G., and Bush, D. F. (2002). Negotiation for starting salary: Antecedents and outcomes among recent college graduates. Journal of Business and Psychology, 16(3), 365-82.

Ployhart, R. E., Nyberg, A. J., Reilly, G., and Maltarich, M. A. (2014). Human capital is dead; long live human capital resources! Journal of Management, 40(2), 371-98.

Romanoff, K., Boehm, K., and Benson, E. (1986). Pay equity: Internal and external considerations. Compensation and Benefits Review, 18(6), 17-25.

Rubenstein, A. L., Eberly, M. B., Lee, T. W., and Mitchell, T. R. (2018). Surveying the forest: A meta-analysis, moderator investigation, and future-oriented discussion of the antecedents of voluntary employee turnover. Personnel Psychology, 71(1), 23-65.

Shaw, J. D., and Gupta, N. (2007). Pay system characteristics and quit patterns of good, average, and poor performers. Personnel Psychology, 60(4), 903-28.

Sinclair, A. L. (2003). The effects of justice and cooperation on team effectiveness. Small Group Research, 34(1), 74-100.

Society for Human Resource Management [SHRM]. (2012). More organizations shift to market-based pay structures. Retrieved from: https://www.shrm.org/resourcesandtools/hr-topics/compensation/pages/pay-structuresshift.aspx.

Sweeney, P. D., and McFarlin, D. B. (2005). Wage comparisons with similar and dissimilar others. Journal of Occupational and Organizational Psychology, 78(1), 113-31.

Toh, S. M., Morgeson, F. P., and Campion, M. A. (2008). Human resource configurations: Investigating fit with the organizational context. Journal of Applied Psychology, 93(4), 864-82.

Trevor, C. O., Reilly, G., and Gerhart, B. (2012). Reconsidering pay dispersion's effect on the performance of interdependent work: Reconciling sorting and pay inequality. Academy of Management Journal, 55(3), 585-610.

Weber, C. L., and Rynes, S. L. (1991). Effects of compensation strategy on job pay decision. Academy of Management Journal, 34(1), 86-109.

Welbourne, T. M., and Trevor, C. O. (2000). The roles of departmental and position power in job evaluation. Academy of Management Journal, 43(4), 761-71.

Williams, M. L., McDaniel, M. A., and Nguyen, N. T. (2006). A meta-analysis of the antecedents and consequences of pay level satisfaction. Journal of Applied Psychology, 91(2), 392-413.

WorldatWork, The Total Rewards Association. (2016). Compensation programs and practices survey. Retrieved at https://www.worldatwork.org/docs/research-and-surveys/Survey-Brief-Survey-on-Compensation-Programsand-Practices-2016.pdf. 